\title{
PREVIOUS NUMERICAL STUDIES WITH DEFORMABLE BALLAST ON BODY IMPACTS AGAINST BUILDING EDGE PROTECTION SYSTEMS
}

\author{
J.C. POMARES ${ }^{1}$, R. IRLES ${ }^{1}$, E. CARRION ${ }^{2}$, A. GONZÁLEZ ${ }^{1}$ \& E.G. SEGOVIA ${ }^{1}$ \\ ${ }^{1}$ Civil Engineering Department, Alicante University, Spain \\ ${ }^{2}$ Building \& Urban Development, Alicante University, Spain.
}

\begin{abstract}
Recent studies with numerical models regarding edge protection systems (EPS), class $\mathrm{C}$ according to standard EN 13374, showed that some requirements are inadequate for human safety. This problem mainly arises when a person is injured by falling directly against the EPS supports.

To analyse this subject, three series of numerical models, in accordance with EN 13374, have been produced. The paper describes these studies, which have been carried out using straight supports, different weight ballasts and also a deformable ballast.

In the first series, impacts against straight supports have been analyzed and a standard EN 13374 ballast has been used. These first studies showed too many high impact factors on the ballast. The obtained values are absolutely inadequate and dangerous to the integrity of the human body. The second series was conducted to know how different weights and shapes of ballast affect the maximum accelerations suffered by the human body. Finally, in the third series, a more deformable ballast has been used to simulate impacts of workers against straight supports, nearest to the real behaviour of a human body.

Results confirm and measure an excessive impact factor suffered by the falling person. Mainly in the first series, with direct impacts of standard ballast against straight supports, acceleration values have been generated that could seriously injure the body or even could kill workers.

The second series showed that different weights and shapes - cylinder or sphere - of ballast affect the acceleration values calculated.

Finally, in the third series, the deformable ballast has achieved results truer than previous studies with the more rigid ballast established by EN 13374.

Keywords: accelerations, deformable ballast, edge protection system, EN 13374, falling person, falls, impact factor, impacts, straight supports.
\end{abstract}

\section{INTRODUCTION}

Workplace accidents cause deep suffering and the loss of many human lives, and their economic cost is high. However, the awareness of the general public regarding safety and health at work tends to be very low. Too often, it is not assigned the priority it deserves. Decent work must be safe work.

Construction produces serious accidents. According to the Spanish Labour Ministry statistics, in 2014 , there were 42,226 construction work accidents, equating to $10.12 \%$ of all work accidents (Fig. 1).

Analysing different types of accidents, statistics show that falls and collisions with stationary objects represent $24.5 \%$ of the total number of accidents (Fig. 2).

To improve safety conditions regarding accidents involving falls, previous studies [1-6] have been conducted, using numerical models of EPS built with finite elements technique. 


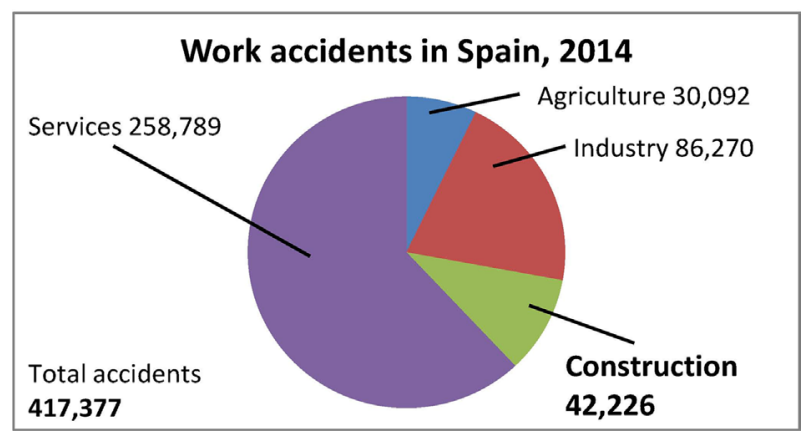

Figure 1: Work accidents in Spain, 2014.

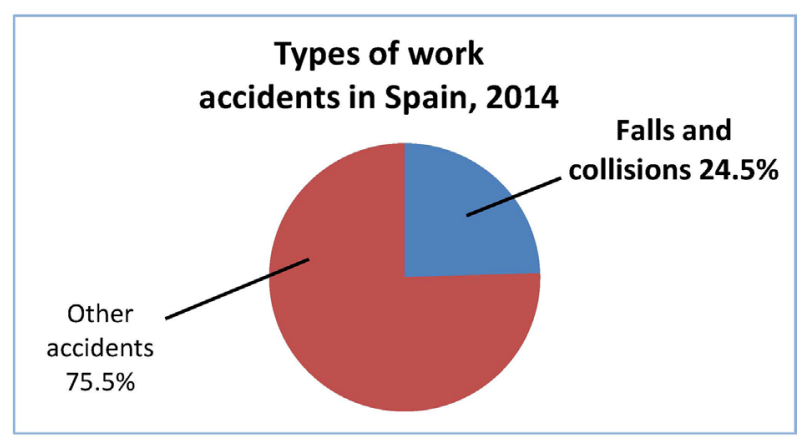

Figure 2: Types of work accidents in Spain, 2014.

Moreover, to confirm these results, some real experiments, in accordance with EN 13374 [7], were carried out using a steel frame, a safety net and other stop surfaces. These experiments were also useful to calibrate the numerical models and to design the original supports of the EPS. Ergonomic support [3] was designed to avoid direct impact when the ballast falls down directly against them, allowing sufficient deflection of the net and avoiding too major injuries on the person that falls. This is an unsolved question in point 6.4 .3 of the current standard EN 13374.

This paper has first studied the impact factor of the ballast against usual straight supports. Next, it has analysed the weight and shape influences of the ballast in relation to its impact factor against the safety net. Finally, it has used soft ballast through the numerical model to simulate, in a more realistic way, the human body's behaviour.

This research is relevant for worker security, and the results could be important for future device-design processes and also to improve the current EN 13374.

\section{DIRECT IMPACTS AGAINST STRAIGHT SUPPORTS}

To simulate victim fall against straight support of an EPS, the specifications laid down in EN 13374 have been followed. The angle of slope to the horizontal is $60^{\circ}$ and the ballast rolls 5 $\mathrm{m}$ before impacting on the support. The EPS has been modelled (Fig. 3) using Ansys finite elements programme [8]. Supports used were a tubular hollow steel bar with a diameter of $40.2 \mathrm{~mm}$, increasing to $60.3 \mathrm{~mm}$. 
Three materials are involved, with the following characteristics:

- The net has a $10 \times 10 \mathrm{~cm}^{2}$ mesh with braids of $610 \mathrm{~N}$ stiffness and weighs $0.008 \mathrm{~kg} / \mathrm{m}$.

- The ballast consists of a diameter of $0.30 \mathrm{~m}$ and weighs $75 \mathrm{~kg}$.

- The steel bracket is a tubular hollow steel bar with a yield limit of $275 \mathrm{~N} / \mathrm{mm}^{2}$.

- The Ansys elements used for each material were:

- Net (Link180). The net behaves in a way that is equivalent to a law of linear elastic behaviour (with adequate parameters), with no resistance to compression and with structural damping [1].

- Ballast (Solid185 and Shell181). This has been defined by a cylinder - $30 \mathrm{~cm}$ in diameter and $75 \mathrm{~kg}$ in weight - that will be launched onto the net.

- Support or metal frame (Beam188) with a tubular cross-section of different diameters and thicknesses.

- Contact elements (Conta and Targe). The contact between the ballast and the support has been defined using certain auxiliary surface elements of insignificant mass and stiffness, which only transmit tension membrane forces and which use the nodes of the support.

- In each case, the data have been obtained for:

- The displacement of the support, and mainly the maximum acceleration that the ballast undergoes in its displacement, which generates the maximum forces that the accident victim can suffer.

Ballast used in these simulations has a high stiffness; steel and rubber elastic moduli are 210,000 and $100 \mathrm{~N} / \mathrm{mm}^{2}$, respectively.

The greater is the support stiffness, the greater the ballast acceleration (Fig. 4). These values lead directly to the maximum forces generated during the worker's fall.

Impact simulations - against the hard straight supports - show that the obtained impact factors, on average $685 \mathrm{~g}$, are absolutely inadmissible for the falling person's health.
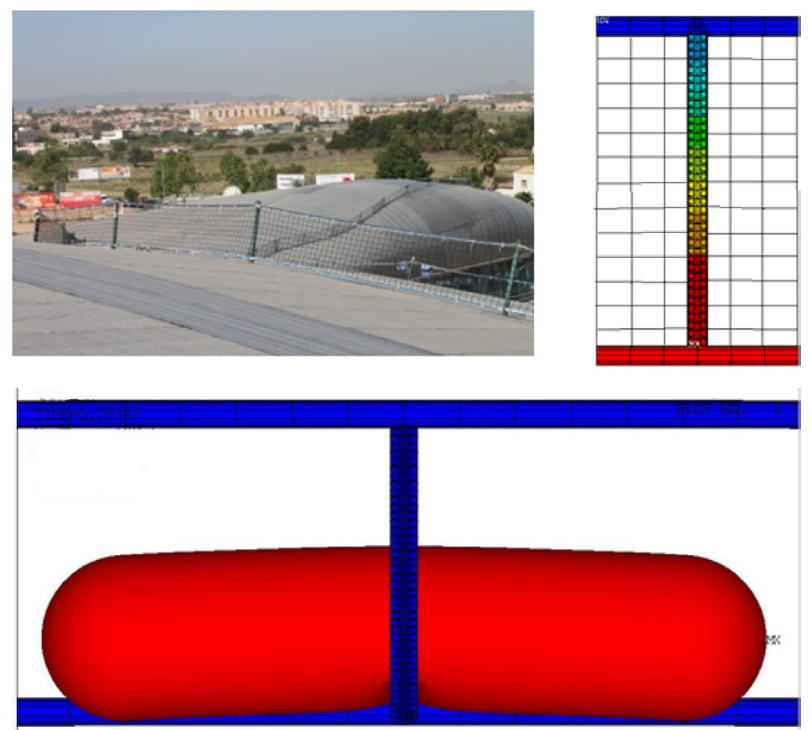

Figure 3: Ballast impact simulation against straight support. 


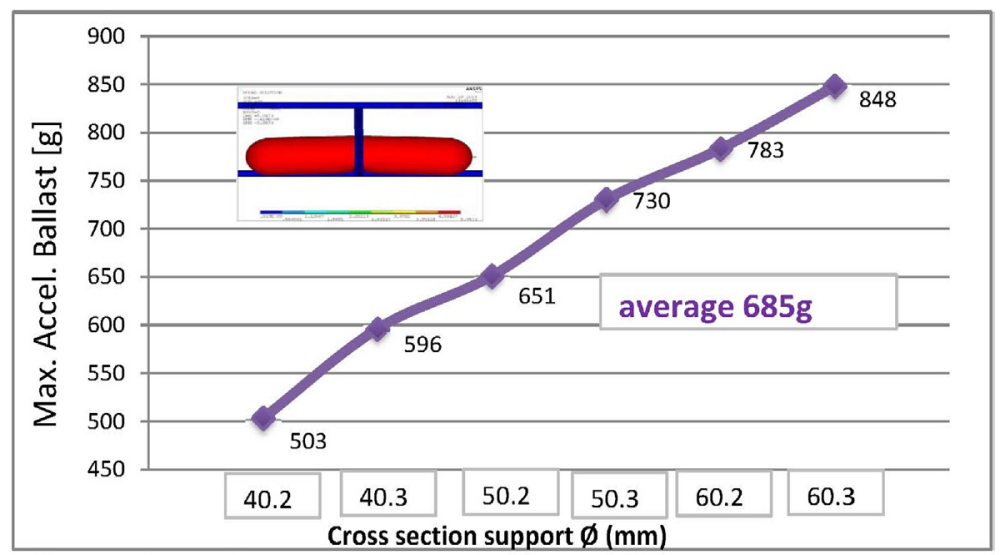

Figure 4: Maximum accel. Ballast against straight support.

Jeffrey R. Davis [9] cites John J. Swearingen's studies (Civil Aeromedical Institute, Columbus). These works show the tolerances of the human face against an impact. In this research, depending on its exact location, different maximum acceleration limits have been obtained:

Nose: $\mathbf{3 0} \mathbf{g}$

Chin: $\mathbf{4 0} \mathbf{g}$

Cheekbones: $\mathbf{5 0} \mathbf{g}$

Forehead: 80-200 g

Teeth: $\mathbf{1 0 0} \mathrm{g}$

These studies received the Metropolitan Award of Honor for Research in Accident Prevention in 1965.

Accelerations obtained in Fig. 4 through finite element models were between $500 \mathrm{~g}$ and $800 \mathrm{~g}$. These values are three to four times higher than the tolerances in the Swearingen studies. Experimental tests to validate the results continue pending at this moment.

\section{THE INFLUENCE OF BALLAST WEIGHT AND SHAPE ON THE IMPACT FACTORS}

The maximum impact factor that a human body can resist depends on multiple factors, the most relevant being:

Concentrated or distributed character of forces.

Human body application point - nose, chin, cheekbones, forehead, teeth, etc.

Direction of forces in relation to the human spine ( $\mathrm{Z}$ direction in Fig. 5).

Duration of the acceleration applied.

Deceleration distance.

Maximum acceleration value.

In this simulation, cross-section supports between $40.2-$ and $60.3 \mathrm{~mm}$ have been used and, moreover, different weights and shapes of ballast have been analysed.

Figure 6 shows the following calculated average accelerations:

$7.3 \mathrm{~g}$ in spherical ballast of $75 \mathrm{~kg}$

$6.2 \mathrm{~g}$ in spherical ballast of $100 \mathrm{~kg}$

$10.9 \mathrm{~g}$ in cylindrical ballast of $75 \mathrm{~kg}$ 


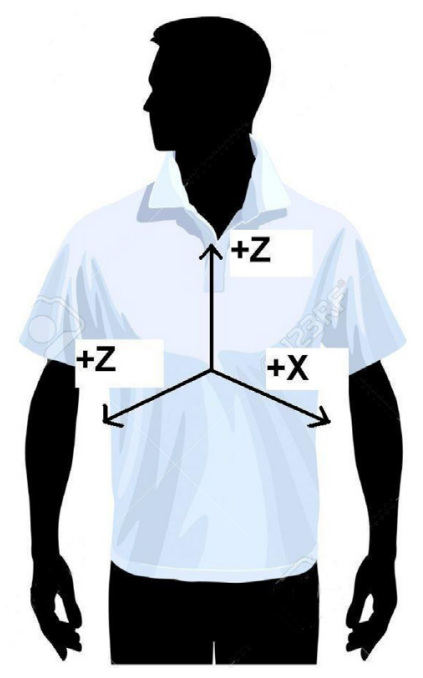

Figure 5: Orthogonal linear axes used in aerospace medicine.

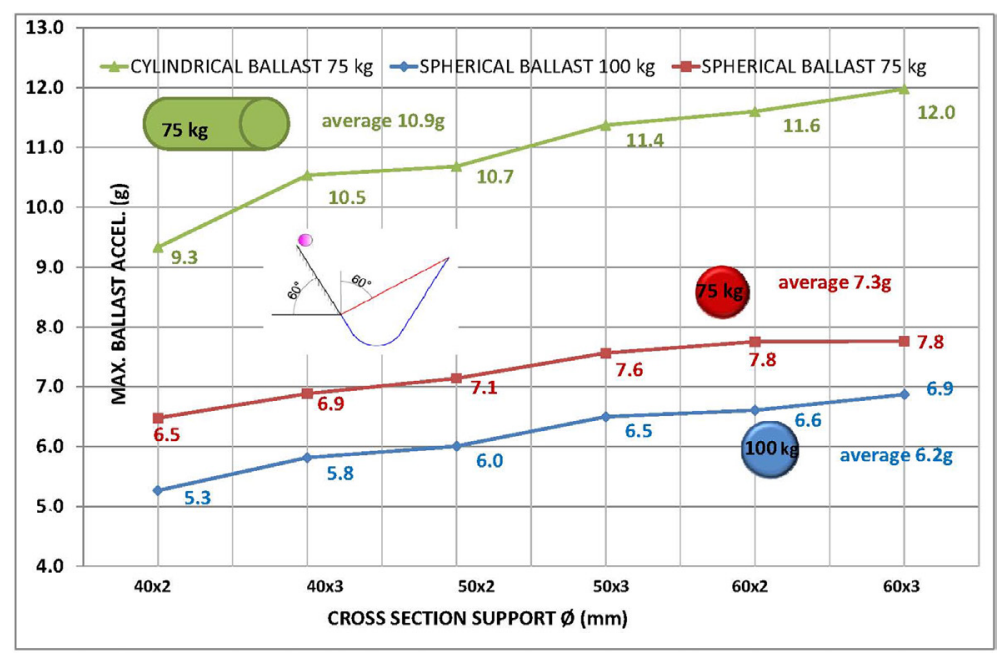

Figure 6: Maximum ballast acceleration.

Figure 7 shows, for the same previous numerical simulations, the following averages of maximum net deflection:

$0.94 \mathrm{~m}$ in spherical ballast of $75 \mathrm{~kg}$

$1.245 \mathrm{~m}$ in spherical ballast of $100 \mathrm{~kg}$

$0.59 \mathrm{~m}$ in cylindrical ballast of $75 \mathrm{~kg}$

The spherical ballast of $75 \mathrm{~kg}$ in this simulation has suffered $17 \%$ more acceleration than the $100 \mathrm{~kg}$ spherical ballast.

The $75 \mathrm{~kg}$ cylindrical ballast in this study has experienced $41 \%$ more acceleration than the $75 \mathrm{~kg}$ spherical ballast. 


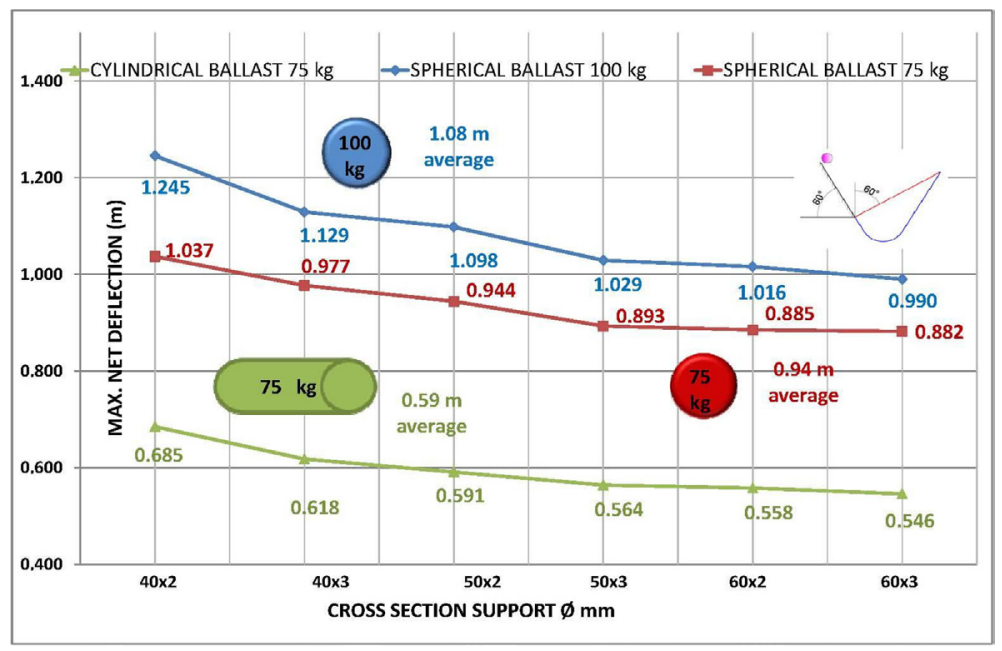

Figure 7: Maximum net deflection.

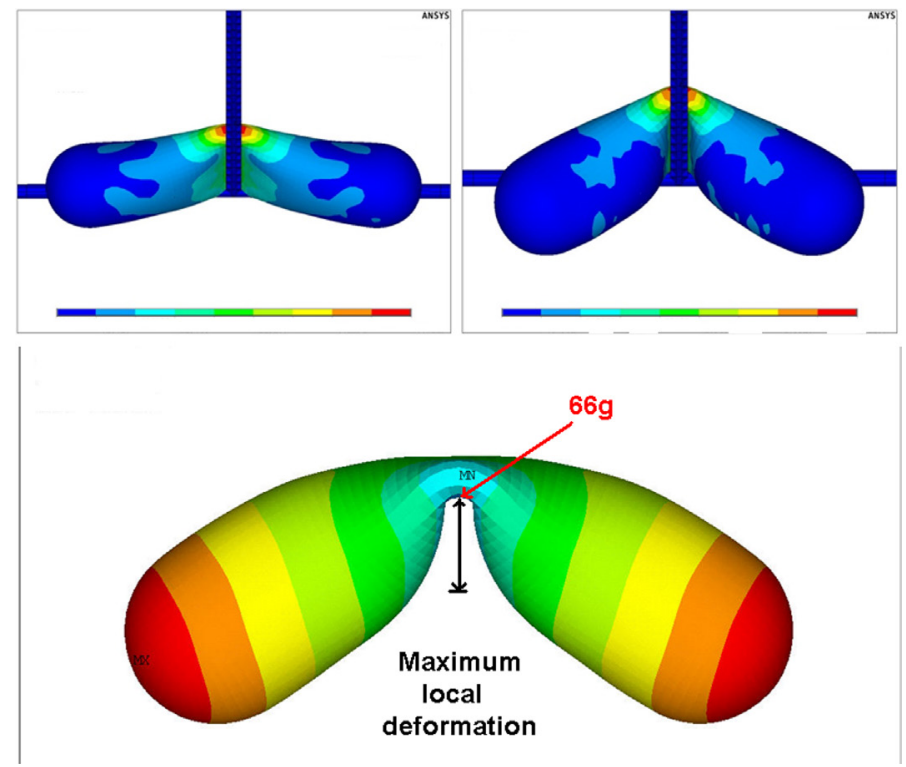

Figure 8: Soft ballast simulation.

Finally, these studies have demonstrated that the weight and shape of the ballast affect the maximum accelerations suffered by the human body.

\section{SOFT AND DEFORMABLE BALLAST SIMULATION}

This work goes on to simulate deformable ballast to analyse the direct impact of a worker against a straight support.

A few deformable ballast simulations with elastic behaviour have been carried out. The ballast used in these simulations has a lower level of stiffness than that of previous studies. 


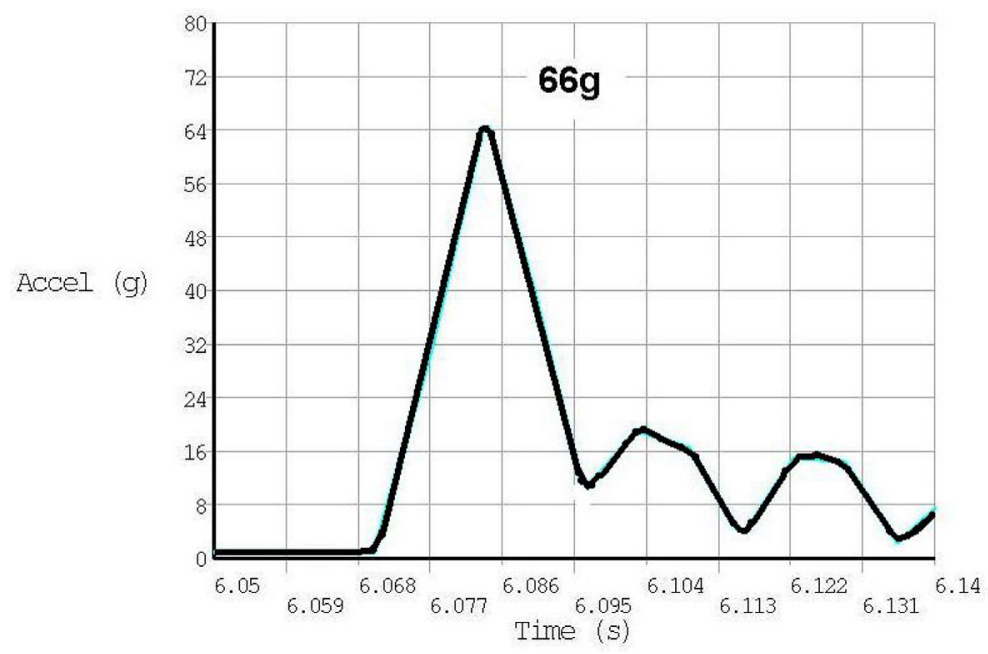

Figure 9: Maximum soft ballast acceleration.

Steel and rubber elastic moduli have been strongly reduced to fictitious values of 25 and 20 $\mathrm{N} / \mathrm{mm}^{2}$, respectively.

Figure 8 shows some images of the maximum local ballast deformation through numerical models (net omitted for more visibility).

Figure 9 illustrates the maximum acceleration suffered by the contact point of the ballast. This value is much lower $-660 \mathrm{~m} / \mathrm{s} 2$ or $66 \mathrm{~g}$ - than the value obtained in Section 2 of this paper, where the average is $685 \mathrm{~g}$, because the energy absorbed by the ballast helps to reduce the impact. However, this energy absorption generates damage to the body, which is to be evaluated. Other ballast parts analysed suffer still lower accelerations.

Soft ballast simulated at this point reflects human body behaviour in a more realistic way than previous works with hard ballast established by EN 13374 and EN 1263-1 [10].

\section{CONCLUSION}

Direct impacts against straight supports - in the first studies - showed too many high impact factors on the ballast that could seriously injure the body or could even kill workers. Accelerations obtained were from 500 to $800 \mathrm{~g}$.

The weight and shape of the ballast - in the second studies - affect the maximum accelerations suffered by the human body.

The spherical ballast of $75 \mathrm{~kg}$ suffers $17 \%$ more acceleration than a 100-kg spherical ballast.

The cylindrical ballast experiences $41 \%$ more acceleration than the spherical ballast with the same weight of $75 \mathrm{~kg}$.

The deformable ballast with elastic behaviour - in the third studies - achieved more realistic results than the previous works with hard ballast established by EN 13374 .

This study shows that acceleration of the ballast contact zone in an impact against a straight support is much lower (66 $\mathrm{g}$ ) than the value obtained with a rigid ballast (685 $\mathrm{g}$ on average). Energy absorbed by the soft ballast helps to reduce the impact.

Local deformation, in the case of a human victim, not only diminishes the maximum accelerations, but it also generates important damage that could be evaluated. Current research focuses on the use of plastic behaviour for the ballast. 


\section{REFERENCES}

[1] Segovia Eulogio, E., Irles Más, R., González Sánchez, A., Maciá Mateu, A. \& Pomares Torres, J.C., Las redes verticales de seguridad en la construcción de edificios II. Informes de la Construcción, 59(505), pp. 37-51, 2007.

[2] Pomares, J.C., Segovia, E.G. \& Irles, R., Personal protection rails for strong impacts. 4th International Conference on Safety and Security Engineering, SAFE, Antwerp (Belgium), 2011.

[3] Pomares, J.C., Ferrer, B., Más, D., Lozano, C., Bresó, S. \& Irles, R., Experimental measure of impact in temporary handrails. 12th International Conference on Structures Under Shock and Impact, SUSI 2012, Kos (Greece), 2012. http://dx.doi.org/10.2495/su120111

[4] Pomares, J.C., Irles, R., Segovia, E.G. \& Boixader, D., Barandillas de protección personal con solicitación dinámica. Informes de la construcción, 65(530), pp. 241-251, 2013.

[5] Ferrer, B., Pomares, J.C., Irles, R., Espinosa, J. \& Más, D., Image processing for safety assessment in civil engineering. Applied Optics, 52(18), pp. 4385-4390, 2013. http://dx.doi.org/10.1364/AO.52.004385

[6] Pomares, J.C., Irles, R., Segovia, E. \& Ferrer, B., Acceleration and deflection analysis for class C edge protection systems (EN 1374-2013) in construction works. Journal of Construction Engineering, 140(8), pp. 31-1, 2014.

[7] EN 13374. Temporary edge protection systems product specification, test methods, CEN 2013.

[8] ANSYS Theory reference 8.1, Ansys Inc. 2003.

[9] Davis, J.R., Johnson, R., Stepanek, J. \& Fogarty, J.A., Fundamentals of Aerospace Medicine, 4th edn., Lippincott Williams \& Wilkings - Wolters Kluwer: Philadelphia (USA), 2008.

[10] EN 1263 Security Nets. Part 1: Security requisites, Test methods. AENOR, 2002. 